\title{
Modeling of Electric Vehicle Charging Load in Different Areas of Distribution Network
}

\author{
Zhou Jiang ${ }^{1 \mathrm{a}^{*}}$, Hairong Zou ${ }^{1 \mathrm{~b}}$ \\ ${ }^{1}$ School of Electrical Engineering, Shanghai Dianji University, Shanghai, 201306, China
}

\begin{abstract}
This paper presents a method of forecasting and modeling of electric vehicle charging load in different regions of distribution network. Firstly, the fixed factors affecting the charging load of electric vehicles are analyzed. The electric vehicles are divided into pure electric and plug-in hybrid electric vehicles, and the charging equipment is divided into ordinary charging equipment and fast charging equipment. Then, the behavior characteristics and psychological factors of electric vehicle users are considered as the random factors influencing the charging load, the investigation statistics and hypotheses are carried out. Finally, the distribution network is divided into different regions, and the charging load model of each region is established based on Monte Carlo simulation. The established model shows that with the increase of penetration rate of electric vehicles in the future, large-scale charging into the power grid will cause impact load in different regions of the distribution network at different times, which provides some reference for the suppression of voltage fluctuation in distribution network.
\end{abstract}

\section{Introduction}

In recent years, the electric vehicle $(\mathrm{EV})^{[1-3]}$ industry has developed rapidly, the market value of new energy vehicle enterprises such as Tesla has increased significantly. It is estimated that the number of electric vehicles in the world will reach 130 million by 2030, at that time, large-scale electric vehicles will be connected to the power grid, which will have adverse effects on the power system $^{[4]}$.

According to the driving characteristics of vehicles, the types of vehicles can be roughly divided into private cars, taxis, buses and official cars. Among them, the first three have high penetration of EV. The travel time of bus is stable and orderly, so its battery is suitable to be used as energy storage equipment for vehicle to grid (V2G) ${ }^{[5]}$ related operation. This paper mainly investigated and analyzed the characteristics of taxi and private EV users' travel behavior.

In reference [6], the load modelling of charging station is studied, the influence of various random factors are considered. In reference [7], the two-stage characteristics of EV charging are considered, the EV charging load in parking lot is modelled. Reference [8-9] consider the fluctuation characteristics of distributed energy in the distribution network, analyze the impact of EV charging on the distribution system through simulation, and puts forward the optimization methods of voltage fluctuation and other problems. At present, most references only consider a single type of EV, and the EV battery level can not represent the advanced level of the industry, in those simulation process, only battery parameters are considered, the interference of battery management system (BMS) ${ }^{[10]}$ on battery charging is not considered. Those statistical analysis of vehicle users' travel behavior is based on the results of the national household travel survey conducted by the U.S. Department of transportation in 2017, but the data is still quite different from the first-tier cities with high EV penetration rate in China.

In this paper, the Tesla Model 3, which has the highest sales volume in recent two years, is selected to represent the average level of Battery electric vehicle (BEV) battery technology in the case of a substantial increase in EV penetration in the future, in order to replace the simulation study of battery charging without considering the intervention of BMS, the real-time charging power of EV is recorded by spot measurement recording method. The influencing factors of EV charging are divided into fixed factors and random factors, and the distribution network is divided into residential area, industrial area and commercial area according to the city planning, and the charging station is considered separately. On the premise of statistical analysis and hypothesis of each influencing factor, the EV charging load of each area of distribution network is modelled based on Monte Carlo simulation.

\section{Model of single EV's charging power}

\subsection{Fixed factors affecting EV charging load}

Before the study of EV charging power model, the fixed factors that have an impact on it should firstly be determined: differences on EV types and differences on charging equipment.

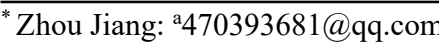

bzouhr@sdju.edu.cn
} 
There are two types of EV that can be connected to the power grid for charging: BEV and Plug-in hybrid electric vehicle (PHEV). In this paper, the fast charging experiment of the current popular Tesla Model 3 is carried out, and the real-time charging power is recorded in the form of sampling point, besides, the battery carried by BYD Han DM is used to represent the battery level of advanced PHEV.

At present, charging equipment can be roughly divided into two categories: fast charging pile and ordinary charging pile. With the construction of charging equipment in old residential areas by relevant departments of power grid and the hot sale of household charging piles, it can be assumed that most EV users will use household charging piles in residential areas in the future, and that fast charging technology will be used by charging stations, besides, it is assumed that EV does not need to queue when being charged. In this paper, the $120 \mathrm{~kW}$ charging pile operated by the State Grid electric vehicle service "e charging" and $7 \mathrm{~kW}$ common charging pile will be selected to represent the power supply capacity of the two types of charging equipment.

According to the statistical data of domestic BEV and PHEV sales from 2019 to 2020 by China Automobile Industry Association, the proportion of two types of EV sales in each month in recent two years is shown in Figure 1. The abscissa 1-24 represent January 2019 to December 2020, the ordinate represents the ratio of BEV to PHEV sales.

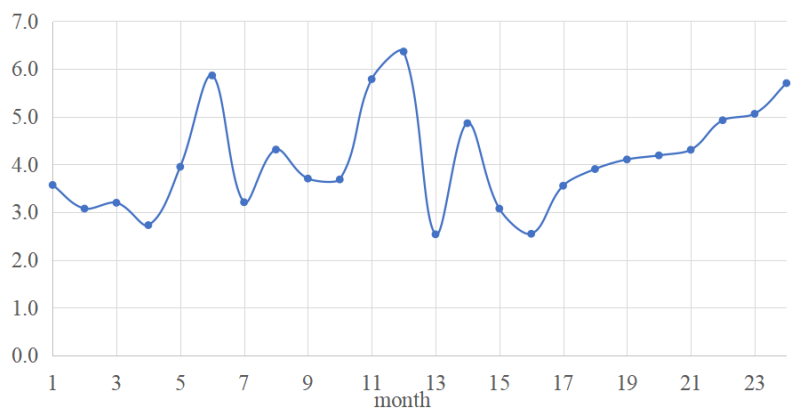

Figure 1. Sales ratio of BEV and PHEV in each month from 2019 to 2020

According to Figure 1, although the ratio of BEV to PHEV monthly sales in 2019 and 2020 has certain volatility, the average value in two years is 4.1 . So it is assumed that the ratio of BEV to PHEV will be kept at 4.1 after several years.

\subsection{Model of measured charging power}

Through the actual experimental test, the power curve of BEV in $120 \mathrm{~kW}$ fast charging is obtained, as shown in Figure 2. Due to the intervention of BMS in the case of fast charging, the actual charging power does not reach the maximum power of $120 \mathrm{~kW}$, and the charging power curve is more complex.

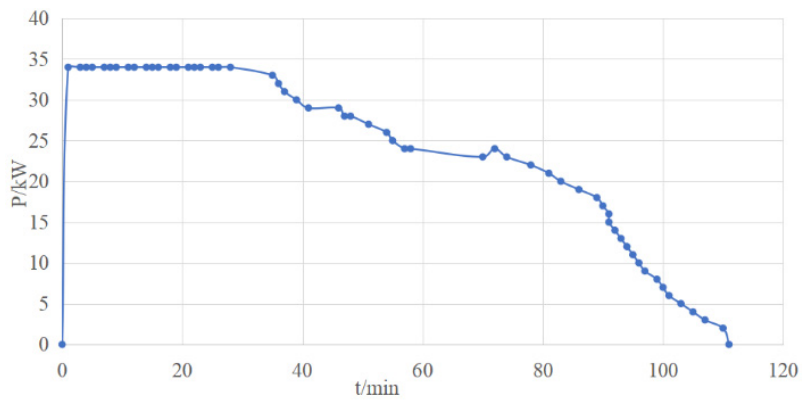

Figure 2. Fast charging P-t curve of BEV

Under ideal state, this paper exclude the short-term fluctuation of voltage and current of charging equipment. When BEV is charged with household $7 \mathrm{~kW}$ charging pile, the power time curve will adopt the two-stage model described in reference [11], as shown in Figure 3.

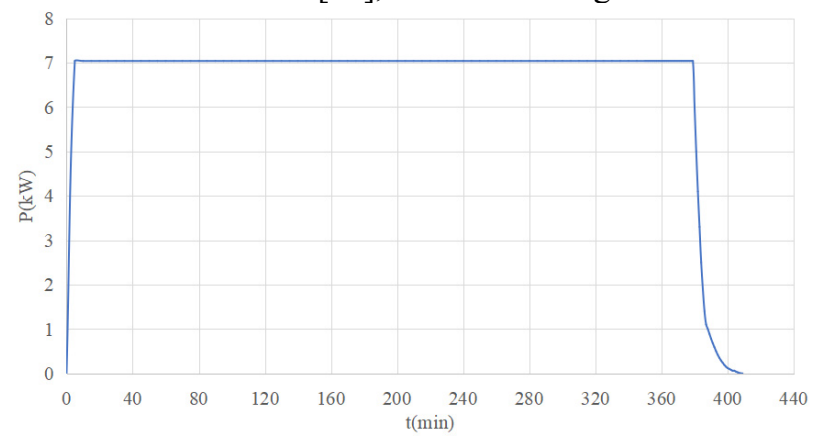

Figure 3. $7 \mathrm{~kW}$ charging P-t curve of BEV

Both PHEV and BEV are equipped with lithium batteries, but the former does not support fast charging technology because of its small capacity. It's assumed that PHEV has the same property as BEV when charged with $7 \mathrm{~kW}$ charging pile. Therefore, the $7 \mathrm{~kW}$ charging P-t curve of PHEV should be as shown in Figure 4.

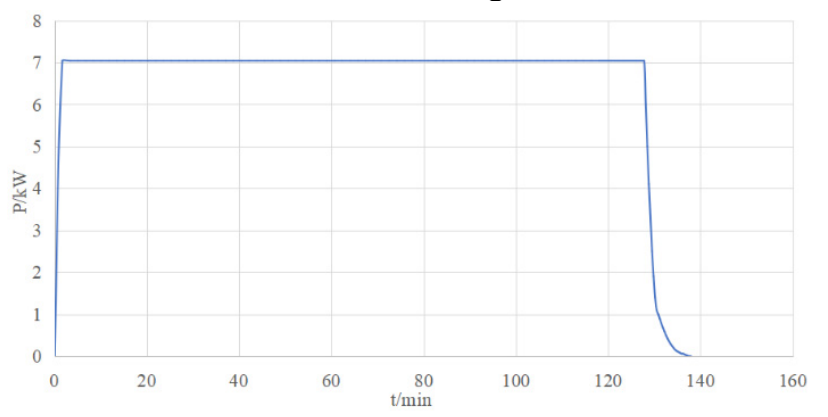

Figure 4. 7kW charging P-t curve of PHEV

\subsection{Simplified model of EV charging}

The structure of charging equipment mainly includes rectifier circuit, low-pass filter and DC-DC converter ${ }^{[11]}$. Among them, the efficiency of DC-DC converter and the power factor of rectifier circuit can reach $96 \%$ and $97 \%$ respectively ${ }^{[12]}$. The above losses have little influence on the overall EV charging load modeling process in a certain area and can be ignored. Therefore, the P-t curve of EV's charging under various conditions is directly simplified to represent the power provided by the grid. 


\subsubsection{Simplified model of $120 \mathrm{~kW}$ fast charging of $B E V$}

Simplify the $120 \mathrm{~kW}$ fast charging model of BEV, and the simplified power model can be expressed by 5 -stage piecewise function, as shown in Figure 5.

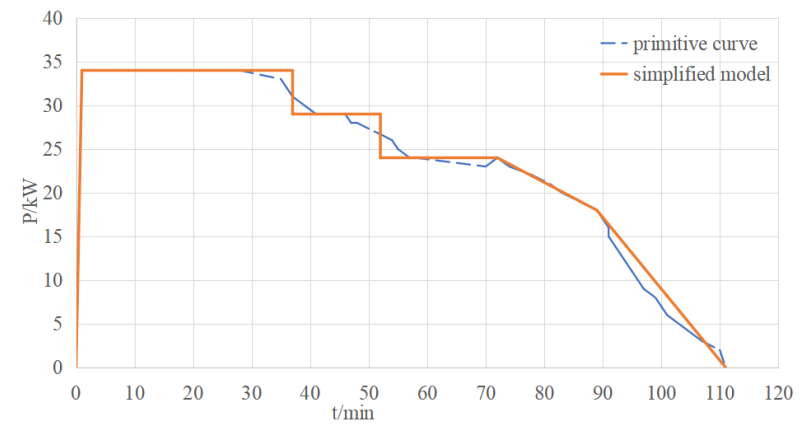

Figure 5. Simplified P-t model of BEV fast charging

According to the P-t curve of BEV, the mathematical formula is shown in equation (1):

$$
\mathrm{P}= \begin{cases}34 & , 0 \leq t \leq 37 \\ 29 & , 37 \leq t \leq 52 \\ 24 & , 52 \leq t \leq 72 \\ (840-t) / 17 & , 72 \leq t \leq 89 \\ 9 \times(111-t) / 11 & , 89 \leq t \leq 111\end{cases}
$$

The relationship between SOC of EV battery and charging power $\mathrm{P}$ is shown in equation (2). According to this, the SOC value of each key time node can be calculated, and the curve diagram of the relationship between SOC and charging time is drawn, as shown in Figure 6.

$$
\mathrm{SOC}=S O C_{0}+\int_{t_{0}}^{t} P \mathrm{~d} t / \mathrm{C}
$$

In this equation, $\mathrm{t}_{0}$ is the time corresponding to $\mathrm{SOC}_{0}$ on the $P$ - $t$ curve, $t$ is the sum of $t_{0}$ and the actual charging time, $\mathrm{C}$ is the capacity of EV battery.

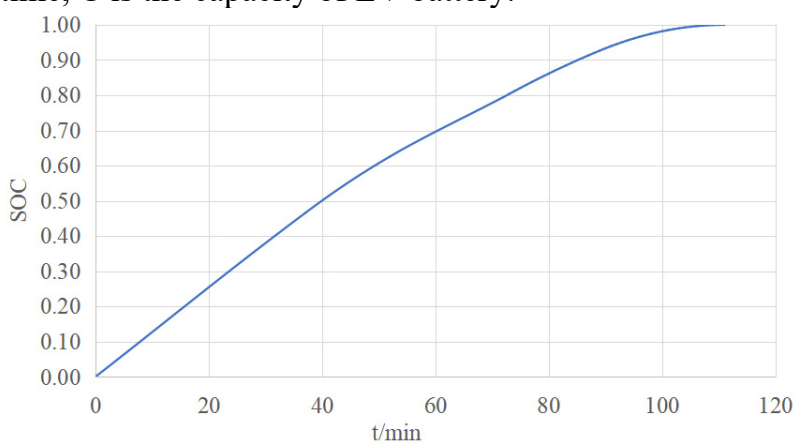

Figure 6. SOC-t curve of BEV fast charging

According to equations (1) and (2), the piecewise function of $\mathrm{t} 0$ with respect to $\mathrm{SOC}_{0}$ can be deduced, as shown in equation (3).

$$
\mathrm{t}_{0}=\left\{\begin{array}{cc}
1364 S^{\prime} C_{0} / 17 & , 0 \leq \text { SOC }_{0} \leq 0.461 \\
\left(2728 S O C_{0}-185\right) / 29 & , 0.461 \leq \text { SOC }_{0} \leq 0.621 \\
\left(2728 S O C_{0}-445\right) / 24 & , 0.621 \leq \text { SOC }_{0} \leq 0.797 \\
140-\sqrt{16937.69-46376 S O C_{0} / 3}, 0.797 \leq S_{O} O C_{0} \leq 0.927 \\
111-\sqrt{60016\left(1-S_{0}\right)} / 3 & , 0.927 \leq \text { SOC }_{0} \leq 1
\end{array}\right.
$$

\subsubsection{Simplified model of $7 \mathrm{~kW}$ charging}

It can be seen from Figure 3 that under the ideal condition of using $7 \mathrm{~kW}$ ordinary charging pile, the charging power of EV battery rapidly decays to 0 in the constant voltage and current limited stage, this process is inefficient. In order to improve the charging efficiency, the constant voltage and current limited stage tends to be shortened or cancelled $^{[13]}$, so the two-stage charging model of EV can be simplified as a single-stage charging model with constant power ${ }^{[14]}$, as shown in Figure 7 , the charging power is maintained at $7.04 \mathrm{~kW}$ in 380 minutes.

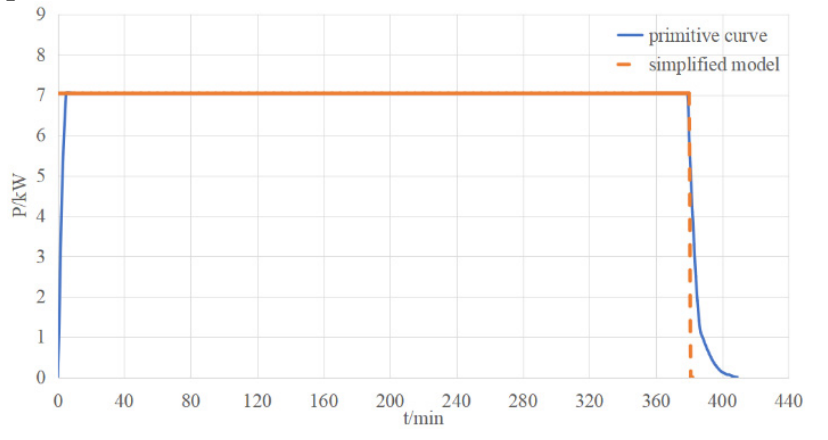

Figure 7. Simplified P-t model of BEV charging with 7kW charging point

Do the same simplification for $7 \mathrm{~kW}$ charging $\mathrm{P}-\mathrm{t}$ curve of PHEV, and get a simplified model for constant charging power of $7.04 \mathrm{~kW}$ in 129 minutes, as shown in Figure 8.

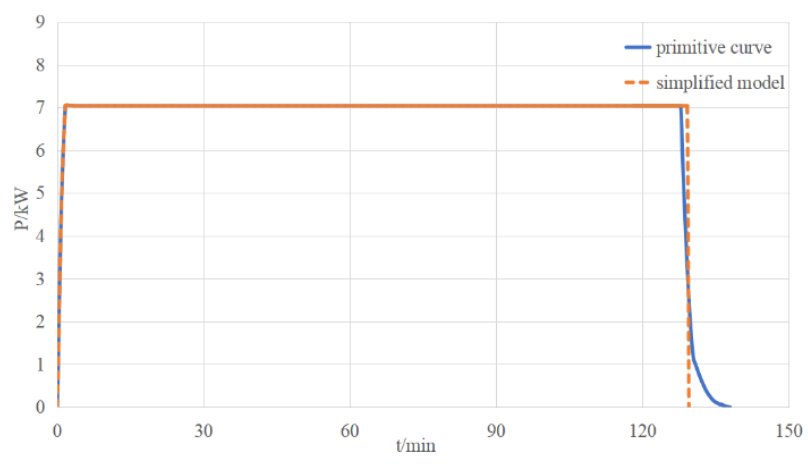

Figure 8. Simplified P-t model of PHEV charging with $7 \mathrm{~kW}$ charging pile

\section{Random factors influencing EV charging characteristics}

According to the "action plan for promoting new infrastructure construction in Shanghai (2020-2022)" issued in May 2020, over 100000 new public EV charging piles will be built in Shanghai between 2020 and 2022. According to the plan of charging equipment transformation for residential area by relevant units of power grid, the following assumptions can be made:

1. Most EV users can use $7 \mathrm{~kW}$ civil charging piles in residential areas, and the power supply capacity of charging equipment is sufficient;

2. Considering that taxis pay more attention to vehicle cost, it is assumed that all taxi models are BEV; 
3. All charging stations adopt fast charging equipment, and the power supply capacity of the equipment is sufficient.

In this context, taking into account some random factors that affect EV charging load is the premise of establishing a more scientific model for domestic EV charging load in the future.

\subsection{Psychological factors of EV users}

\subsubsection{Choice of charging equipment}

Charging equipment can be divided into ordinary charging equipment and fast charging equipment. Fast charging equipment charge the battery of EV with large current, which will not only bring great impact to the power grid, but also reduce the service life of $\mathrm{EV}$ battery ${ }^{[15]}$. Therefore, it can be assumed that private cars do not use fast charging equipment in non emergency on weekdays. And taxi EV users pay more attention to efficiency, almost all of them choose to use fast charging pile.

\subsubsection{Willingness to accept the guidance of TOU}

For EV users equipped with household charging piles in residential areas, their charging behavior can be roughly divided into two categories according to the different times to start charging:

1. Start charging directly at the end of the trip;

2. Start charging at the start time of the period of low electricity price which is 22:00.

According to the statistics of car users' travel situation, there is still a big gap between the end time of most car users' last trip and 22:00. Even so, it takes a long time for EV to be charged with $7 \mathrm{~kW}$ charging pile, for example, when EV starts charging at 20:00, only the first two hours of charging is not included in the low electricity price. Therefore, it is necessary to make assumptions of different proportion on the willingness of private car EV users to accept time of use price guidance, assuming that the proportion of receiving the guidance of time of use (TOU) is $0 \%, 10 \%, 20 \%$ and $40 \%$ respectively.

According to the statistics of about $20000 \mathrm{EV}$ charging information of a charging station with taxi as the main customer, the data of the number of vehicles charging in different periods are obtained, as shown in Figure 9. The charge of fast equipment is higher, so Taxi EV users are more willing to accept TOU price guidance.

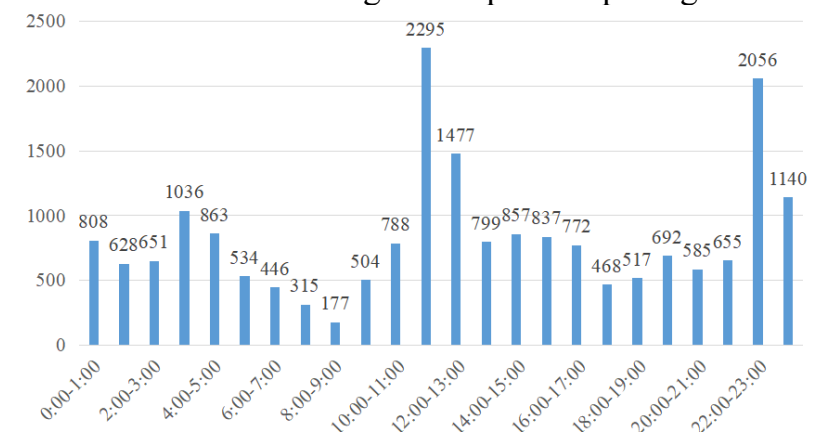

Figure 9. Statistics of vehicle arrival time at a charging station

\subsubsection{Distribution law of $\mathrm{SOC}_{0}$}

According to the statistics of about 16000 charging information of an $\mathrm{EV}$ charging station, the statistical data of $\mathrm{SOC}_{0}$ is evenly divided into 30 intervals from $1 \%$ to $99 \%$, and the curve fitting is carried out according to the distribution of $\mathrm{SOC}_{0}$. The results are shown in Figure 10.

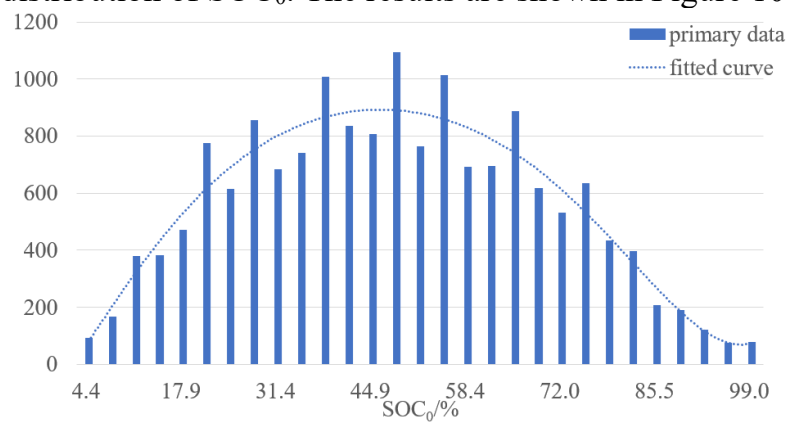

Figure 10. distribution of $\mathrm{SOC}_{0}$ and its fitting curve

By analyzing the distribution and fitting curve results of $\mathrm{SOC}_{0}$, it can be concluded that the distribution basically conforms to the normal distribution with the average value of $47.85 \%$ and the standard deviation of $20.98 \%$, which represents the distribution of $\mathrm{SOC}_{0}$ of all $\mathrm{EV}$ users during charging.

\subsection{Characteristics of EV users' travel and charging behavior}

Due to the great differences on travel behavior characteristics between taxi and private car, it is necessary to investigate and analyze the travel behavior characteristics of both users.

\subsubsection{Characteristics of taxis' travel and charging behavior characteristics}

According to the analysis of Figure 9, it can be concluded that the taxi charging time has a certain regularity: 7:009:00 in the morning and 17:00-19:00 in the afternoon are the traffic peak, which is also the trough period of taxi charging; 11:00-13:00 at noon has fewer taxi orders, and the drivers need to have lunch, so this time period is the peak period of taxi charging in the daytime; 22:00-23:00 at night is another peak period of taxi charging, which is the peak period, and the reason is the guidance of TOU. Therefore, the distribution law of taxi arrival time can be represented by the distribution law shown in Figure 9.

\subsubsection{Characteristics of private cars' travel and charging behavior}

Based on the analysis of characteristics of private cars' travel and charging behavior, the user groups can be divided into three categories: Group A chooses to use charging equipment near the workplace for charging; Group B uses charging piles equipped in parking spaces in residential areas for charging; Group $\mathrm{C}$ chooses to use fast charging equipment at charging station due to 
emergency. The charging behaviors of the above three groups are assumed as shown in Table 1.

Table 1. Classification of private car users

\begin{tabular}{|c|c|c|c|}
\hline $\begin{array}{c}\text { group } \\
\text { classification }\end{array}$ & A & B & C \\
\hline $\begin{array}{c}\text { charging } \\
\text { location }\end{array}$ & $\begin{array}{c}\text { working } \\
\text { place }\end{array}$ & residential area & $\begin{array}{c}\text { charging } \\
\text { station }\end{array}$ \\
\hline $\begin{array}{c}\text { charging } \\
\text { equipment }\end{array}$ & $\begin{array}{c}7 \mathrm{~kW} \\
\text { charging pile }\end{array}$ & $\begin{array}{c}7 \mathrm{~kW} \text { charging } \\
\text { pile }\end{array}$ & $\begin{array}{c}\text { fast charging } \\
\text { equipment }\end{array}$ \\
\hline $\begin{array}{c}\text { time to start } \\
\text { charging }\end{array}$ & $\begin{array}{c}\text { the end time } \\
\text { of the first } \\
\text { trip }\end{array}$ & $\begin{array}{c}\text { the end time of } \\
\text { the last trip }\end{array}$ & $\begin{array}{c}\text { random } \\
\text { distribution in } \\
\text { a day }\end{array}$ \\
\hline proportion & $\alpha$ & $\beta$ & $(1-\alpha-\beta)$ \\
\hline
\end{tabular}

Based on the investigation and statistics of the travel behavior characteristics of private car users, the statistical result of the first end travel time of private car users on weekdays is obtained, as shown in Figure 11. The result is suitable for describing the distribution law of the time to start charging of group A.

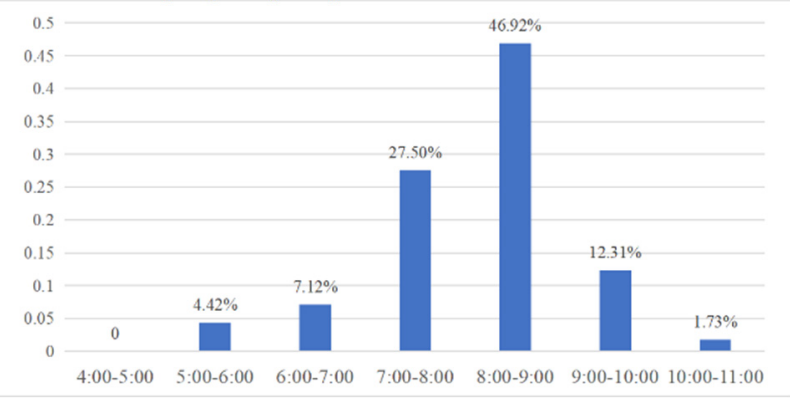

Figure 11. distribution of the end time of first trip of private car users on weekdays

The statistical result of the end time of the last trip of private car users on weekdays is shown in Figure 12, and the field survey result of the end time of the last trip of vehicles in a residential area in Shanghai Lingang from 17:00 to 20:00 is shown in Figure 13.

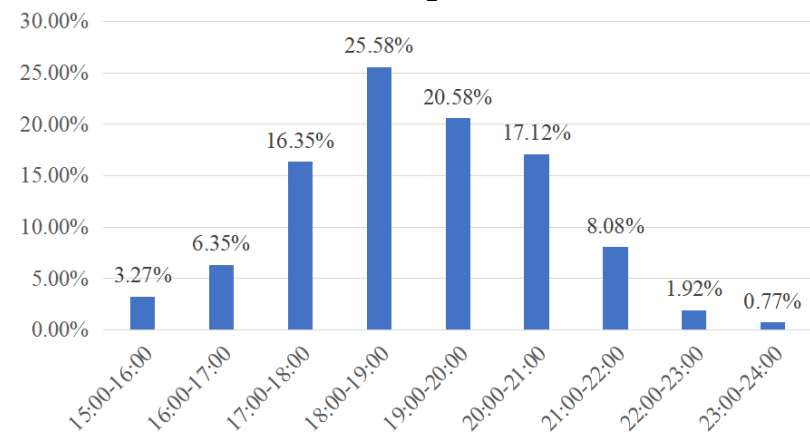

Figure 12. distribution of the end time of last trip of private car users on weekdays

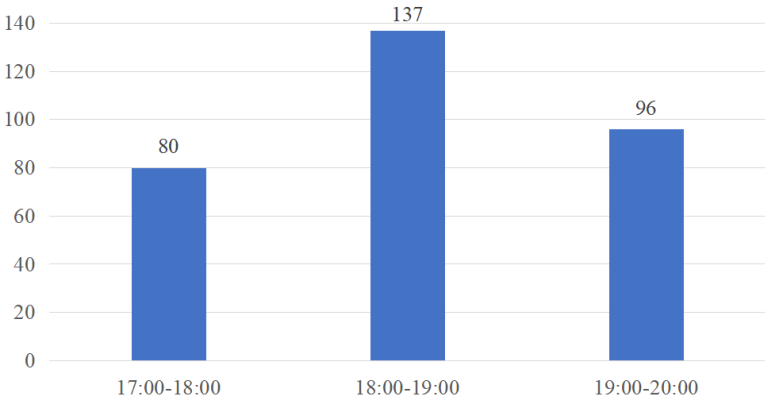

Figure 13. the number of vehicles that end their last trips between 17:00 and 20:00 on a working day in a residential area of Lingang

Compared with Figure 12 and Figure 13, it can be concluded that the distribution law of the former is basically applicable to the actual situation, so the result is applicable to describe the distribution law of the time to start charging of group B.

\section{Modeling of regional EV charging load}

\subsection{Simplification of EV users' charging behavior}

Considering the convenient charging conditions of EV in the future, it is assumed that EV will be fully charged every time they are charged, and that the EV users guided by TOU will start charging at 22:00.

Literature [16] shows that $84.25 \%$ of vehicle users' daily mileage is within $60 \mathrm{~km}$, but with the expansion of urban area and the extension of road distance, it can be assumed that the charging mode adopted by BEV users is charging once every 5 days on average, that is, $20 \%$ of private car BEVS are connected to the power grid every day. PHEV has a little less dependence on electric energy, and its charging mode is assumed to be charging once every 7 days on average.

\subsection{Modeling process of regional EV charging load based on Monte Carlo simulation}

Firstly, we need to consider the differences of charging equipment, EV types and EV user groups in different regions. On weekdays, group A charge in residential area, group B charge in industrial area and business area, and group $\mathrm{C}$ choose fast charging due to emergency situation and needs to arrive at charging station. The EV types of group A and group B include BEV and PHEV, but PHEV does not support fast charging, so it is not included in group C. In addition, it is assumed that taxis only choose charging stations for charging.

After comprehensive consideration of the above factors, the EV charging load of each area is modeled based on Monte Carlo simulation using Matlab, and the modeling process is shown in Figure 14. 


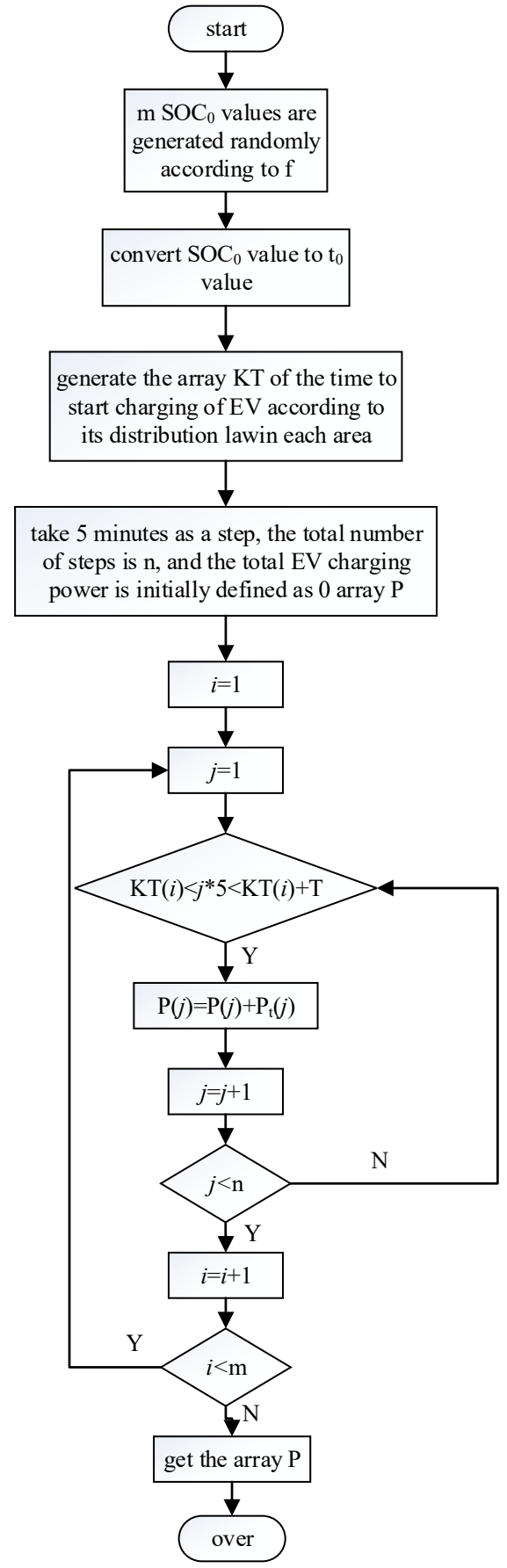

Figure 14. flow chart of modeling of EV charging load based on Monte Carlo simulation

In the flow chart above, $\mathrm{f}$ represents the distribution law of $\mathrm{SOC}_{0}$, Pt represents the charging power of a vehicle at a certain time, and $\mathrm{T}$ represents the time required for SOC to charge from 0 to full.

\subsection{Model of EV charging load of different areas in distribution network}

The sites of EV charging may be in industrial areas, commercial areas, residential areas and fast charging power stations, the future distribution of charging stations in each area is unknown, so charging stations will not be classified into other areas, and the industrial and commercial areas can be regarded as the working places of EV users on weekdays.

Assuming $\alpha=20 \%, \beta=70 \%$, so the proportion of group $\mathrm{C}$ is $10 \%$. Considering the population flow, it is assumed that the total population of residential areas is different from that of industrial and commercial areas, but the proportion of group A, B and C is the same.

\subsubsection{Residential area}

The residential area is equipped with $7 \mathrm{~kW}$ charging piles, and type of car here is private car, the time for these vehicles to start charging is represented by the distribution law of the end time of last trip time as shown in Figure 11. Assuming that there are 47000 people in residential area, when the penetration rate of $\mathrm{BEV}$ is $50 \%$, the number of $\mathrm{BEVs}$ in residential area is 23500 . According to $\beta=70 \%$, the population of group B is 16500 , then according to the charging behavior of charging once every five days, about $3300 \mathrm{BEV}$ s are charged every day. According to the sales ratio of BEV / PHEV of 4.1, it can be concluded that there are about 575 PHEVs connected to the distribution network every day in residential area.

The modeling result of $\mathrm{EV}$ charging power in residential area based on Monte Carlo simulation is shown in Figure 15.

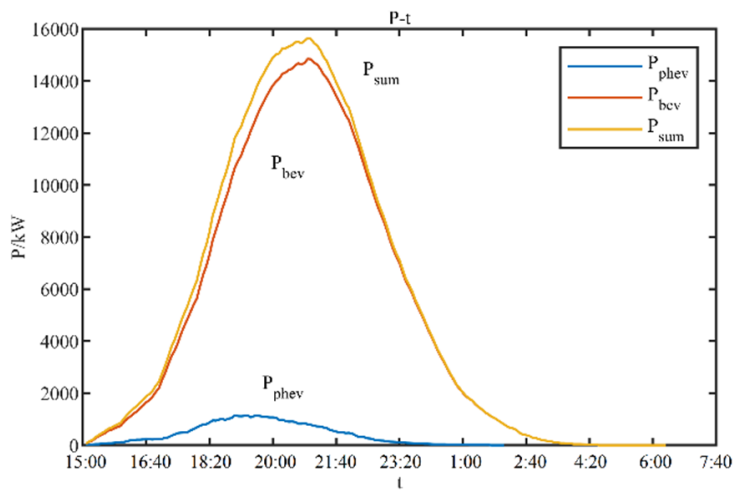

Figure 15. model of EV charging load in residential area

According to the model shown in Figure 15, EV charging in the residential area with the above population size will form an impact load and reach a peak around 21:00, which may reach more than $16000 \mathrm{~kW}$ due to the fluctuation of random factors.

\subsubsection{Industrial area and commercial area}

The characteristics of cars' travel at industrial area and business area on weekdays are similar, which can be regarded as the end of EV users' first trip. Its distribution law of the time to start charging of EV is shown in Figure 9. Assuming that the population size of the business area and industrial area is 40000 , the total $\mathrm{EV}$ penetration rate is $50 \%$, and $\alpha=20 \%$, the population size of group $\mathrm{A}$ is about 4000. On average, 643 BEVS and 142 PHEVs are connected to the power grid for charging every day. The model of EV charging load in industrial and commercial areas is shown in Figure 16. 


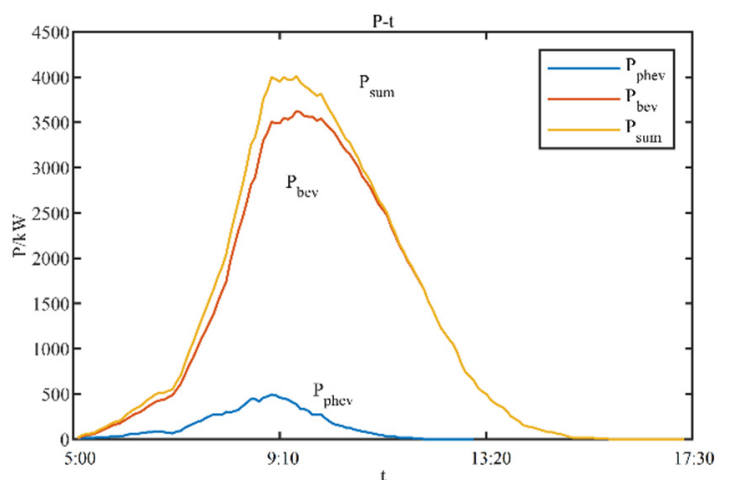

Figure 16. model of EV charging load in industrial and commercial area

It can be concluded from Figure 16 that the fluctuation of EV charging load in industrial and commercial area is similar to that in residential area, but the time period is different. The EV charging load of industrial and commercial area is smaller than that of residential area, but it overlaps with the peak of other traditional loads in the area, which will form an impact load.

\subsubsection{Charging station}

The main customer group of charging stations is taxis, followed by private cars in case of emergency. The average number of taxis charging every day is 2000 , and private cars in case of emergency account for $10 \%$ of the total number of BEVs in residential areas, industrial areas and commercial areas, which is 3950 . Among them, the distribution law of the time to start charging of taxis is shown in Figure 9. In case of emergency, there is no such a clear distribution law, so the random point casting method is used to simulate. Finally, the load model of charging station is obtained, as shown in Figure 17.

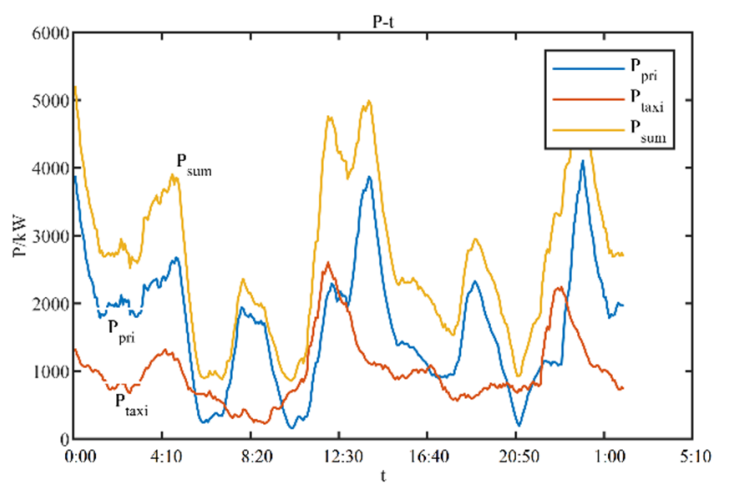

Figure 17. model of EV charging load at charging station

It can be seen from Figure 17 that the charging power of a single EV is high and the charging time is short, while the time to start charging of taxis has a certain distribution law. Therefore, the load variation with time of the charging station is greatly affected by the emergency charging vehicles, and the fluctuation is large.

\subsection{Model of EV charging load in residential area considering the guidance of TOU}

Suppose that when the proportion of EV users guided by TOU is $10 \%, 20 \%$ and $40 \%$ respectively, such proportion of EV users choose to start charging at random between 22:00 and 23:00. The P-t curve of EV charging in residential area is simulated by Monte Carlo, and result is shown in Figure 18.

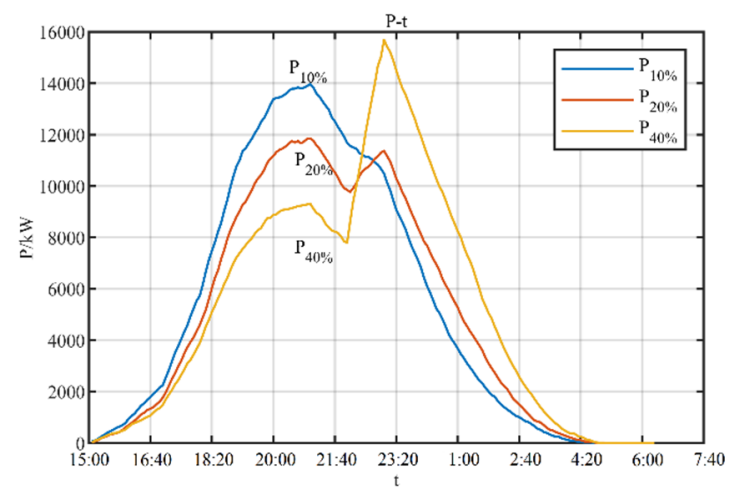

Figure 18. P-t curve of EV charging in residential areas with different proportion guided by TOU

It can be concluded that when $20 \%$ of EV users accept the guidance of TOU price, the curve of EV charging load in residential area is smooth and the peak value is lower. When $40 \%$ of EV users accept the guidance of TOU price, even if the peak load is higher than the former, the peak load appears later, between 23:00-24:00, which is in the trough period of traditional residents' load ${ }^{[17]}$.

\section{Conclusion}

1) In this paper, the fixed factors affecting EV charging load are analyzed. The EV types that affect the power grid are divided into BEV and PHEV, and the charging equipment is divided into ordinary charging pile and fast charging equipment. Due to the intervention of vehicle's BMS in the case of fast charging, the curve of BEV's charging power with time is more complex, and the fast charging power model of BEV is simplified as a mixed form of linear and ladder.

2) The selection of charging equipment, guidance of TOU, distribution of SOC0 and characteristics of travel behavior of private cars and taxis are listed as the random factors influencing EV charging load. The statistical distribution of $\mathrm{SOC}_{0}$ was fitted to obtain an approximate normal distribution model. The users of private cars are divided into three groups according to different charging locations, and the other factors mentioned above are statistically analyzed.

3) The distribution network is simply divided into residential area, industrial area and commercial area, and the fast charging stations are listed separately. According to the differences of population in each area and characteristics of EV users' behavior, the EV charging load of each area is modeled based on Monte Carlo simulation. In addition, considering the different guiding situation of TOU, the EV charging load of residential area is modeled again under different assumptions. According 
to the models of EV charging load of each area, it can be concluded that the charge of a large number of EV will form the impact load of the distribution network in the can provide a reference for the study of the impact and optimization of EV charging load in different areas of distribution network.

4) This paper only models the EV charging load on weekdays, while the travel behavior characteristics of car users on rest days still need to be counted. The endurance of EV will be affected by temperature, so, region, season, climate and other factors will affect EV charging load. In addition, the actual operation of the future distribution network is also affected by traditional load, distributed energy and other factors, therefore, many factors need to be taken into account in TOU strategy for EV users.

\section{References}

1. B. Zeng, Y. Luo, C. Zhang, et al. Assessing the impact of an EV battery swapping station on the reliability of distribution systems. Applied Sciences, 10 (22): 8023-8023 (2020)

2. Y. Ai, X. Hu, X. Zhang, et al. Analysis and study of compact inductive power transfer systems for EV charging. Journal of Power Electronics, 21: 829-839 (2021)

3. Q. Guo, X. Liang, D. Xie, et al. Efficient integration of demand response and plug-in electrical vehicle in microgrid: environmental and economic assessment. Journal of Cleaner Production, 291(2):125581 (2021)

4. J. Zheng, Z. Yan, W. Li, et al. Analysis on the impacts of electric vehicle disorderly charging on power grid load based on Monte Carlo method. Electric Drive Automation, 41 (05): 1-5 (2019)

5. J. Mina, K. Abdollah, N. Taher, et al. Stochastic synergies of urban transportation system and smart grid in smart cities considering V2G and V2S concepts. Energy, 215 (PB). (2021)

6. Y. Hu, Y. Pi, J. Cui, et al. Research on electric vehicle charging station modeling. Power System Protection and Control, 45 (08): 107-112 (2017)

7. Y. Rao, X. Zhang, Y. Rao, et al. A practical probability load model of electric vehicles future, and the superposition of traditional load and EV charging load will pose a certain threat to the safe and stable operation of the distribution network. The models considering charging by stages. Electrical Measurement \& Instrumentation: 1-8[2021-04-07]. http://kns.cnki.net/kcms/detail/23.1202.TH.2020082 7.1606.016.html.

8. L. Xu, G. Yang, Z. Xu, et al. Impacts of electric vehicle charging on distribution betworks in Denmark. Automation of Electric Power Systems, 35 (14): 18-23 (2011)

9. Z. Zhang, G. Hu, R. Li, et al. Optimization of distributed generation output in electric vehicles integrating into distribution network. Power System Protection and Control, 46 (06): 120-127 (2018)

10. Y. Gao, C. Zhu, X. Zhang, et al. Implementation and evaluation of a practical electrochemical-thermal model of lithium-ion batteries for EV battery management system. Energy. (prepublish, 2020)

11. J. Zheng, M. Dai, M. Zhang, et al. Load cluster characteristic and modeling of EV charge station in residential district. Proceedings of the CSEE, 32 (22): 32-38+21 (2012)

12. C. Xia, K. Liu, Y. Guo, et al. Implementation of a bidir ectional DC/DC converter in the electric vehicle. Power Electronics, 40 (01): 70-72 (2006)

13. S. Yang, M. Wu, J. Jiang, et al. An approach for load modeling of electric vehicle charging station. Power System Technology, 37 (05): 1190-1195 (2013)

14. L. Tian, S. Shi, Z. Jia. A Statistical Model for Charging Power Demand of Electric Vehicles. Power System Technology, 34 (11): 126-130 (2010)

15. C. Gao, L. Zhang. A Survey of Influence of Electrics Vehicle Charging on Power Grid. Power System Technology, 35 (02): 127-131 (2011)

16. GS Service. Transport Statistics Bulletin National Travel Survey: 1997/99 Update. (2000)

17. H. Xu, S. Miao, T. Qian, et al. A Modeling Strategy for Charging Loads of Large-Scale Electric Vehicles Considering Multi-days Spaced Charging Mode. Transactions of China Electrotechnical Society, 30 (09): 129-137 (2015) 